\title{
Vai trò của yếu tố văn hóa trong nền móng kinh tế
}

\author{
Bạch Ngọc Chiến \\ Vương Quân Hoàng \\ Tạp chí Kinh tế và Dự báo (ISSN: 0866-7120) \\ Vol. 47, Số 17 (Serial 601) \\ Tháng 9-2015
}

Bạch NC \& Vương QH. (2015). Vai trò của yếu tố văn hóa trong nền móng kinh tế. Kinh tế và Dự báo 48(17), No. 17(601), tr. 18-20. 


\title{
Vai trò của yếu tố văn hóa trong nền móng kinh tế
}

BACH NGOQC CHIẾN ${ }^{*}$ VƯỞंG QUÂN HOÀNG**

\begin{abstract}
Trong sự phát triển của xã hội, kinh tế và văn hoá có mối quan hệ hữu cơ và tác động qua lại. Tuy nhiên, phải tới những thập kỷ gần đây, vấn đề phát triển kinh tế dựa trên nền tảng văn hoá mởi được chú ý, được khẳng định là một quy luật tất yếu khách quan. Mỗi quốc gia chỉ có thể phát triển năng động, hiệu quả và bền vững chừng nào quốc gia đó đạt được sự kết hợp hài hoà giữa kinh tế với văn hoá trong tiến trình phát triển.
\end{abstract}

\section{XƯƠNG SỐNG CỦA SỰ PHÁT TRIỂN}

Nền móng kinh tế của xã hội chính là các yếu tố đầu vào của quá trình sản xuất - dịch vu, như: đất đai, nguồn vốn, lao động và công nghệ. Còn yếu tố văn hóa, mặc dù nhiều người đề cao giá trị của yếu tố này trong xã hội hiện đại, nhưng lai ít được xem là nguồn lực quan trọng đối với phát triển kinh tế (Panagiotis E. Petrakis, 2014)

Đã có nhiều nhà nghiên cứu thực hiện những công trình công phu nhằm làm sáng tỏ lợi ích to lớn của hệ thống văn hóa đối với phát triển kinh tế - xã hội ở nhiều quốc gia, qua nhiều giai đoạn lịch sử khác nhau (Lawrence E. Harrison and Samuel P. Huntington, 2000), tuy nhiên văn hóa trong địa hạt nghiên cứu kinh tế, xét về tổng quan, vẫn chỉ ở vị trí khiêm tốn, thậm chí còn bi đặt bên lề.

Song, thực tiễn cuộc sống ngày càng cần đến sự chấp nhận trước những khác biệt, sự cởi mở trao đổi để hợp tác và sẵn sàng điều chỉnh hài hòa lợi ích. Từ đó, sư thấu hiểu những tác nhân cấu thành, cũng như phương thức vận hành của hệ văn hóa trở nên cần thiết hơn, đặc biệt là khi nhu cầu đời sống ngày càng cao và con người đang dần ý thức về sự cạn kiệt tài nguyên.

Vai trò mờ nhạt của văn hóa trong nghiên cứu kinh tế - xã hội kéo dài tới tận cuối thế kỷ 20 và Avner Greif chỉ ra nguyên nhân cu thể cho tình trang này là "thiếu phương pháp tiếp cận hệ thống văn hóa khi đề cập tới mối quan hệ giữa văn hóa và cấu trúc thể chế”, hay nói cách khác, đó là sự hạn chế về năng lực khi "áp dụng thất bại cấu trúc thể chế đã từng thành công" (Avner Greif, 1994). Không phải đợi đến xã hội hiện đại, thì yếu tố văn hóa mới đóng vai trò quan trọng trong việc định hình quỹ đạo phát triển xã hội thành những hệ thống có đặc trưng riêng, mà trước đó, lịch sử phát triển của thế giới Hồi giáo và các vùng sử dụng ngôn ngữ Latinh đã thể hiện rõ vai trò này.
Cụ thể, thương nhân Hồi giáo ở thế kỷ 11 đã sớm có niềm tin văn hóa giống với "xã hội tập thể" đương đại - thể hiện phổ biến ở các nền kinh tế đang phát triển. Trong khi đó, những thương nhân nói tiếng Latinh lại đặt niềm tin vào giá tri văn hóa giống với "xã hội cá nhân" - thể hiện phổ biến ở các nền kinh tế phát triển phương Tây. Tại xã hội tập thể, cấu trúc xã hội được tách biệt theo nghĩa "tương tác kinh tế", còn xã hội cá nhân chủ yếu diễn ra giữa các thành viên của một nhóm có chung tôn giáo, dân tộc, hoặc huyết thống. Ở các tương tác này, việc thực thi thỏa ước được đảm bảo thông qua các thể chế kinh tế và xã hội "không chính thức". Các thành viên trong xã hội tập thể cảm nhận sự tham gia của mình vào đời sống của các thành viên khác trong cùng nhóm. Đồng thời, sự bất hợp tác là đặc tính của mối quan hệ giữa thành viên thuộc các nhóm khác nhau. Trong xã hội cá nhân, cấu trúc xã hội được thể hiện như sau: giao dịch kinh tế được thực hiện bởi những người thuộc các nhóm khác nhau và mỗi cá nhân thường xuyên dich chuyển từ nhóm này qua nhóm khác. Việc thực thi thỏa ước được đảm bảo thồng qua các tổ chức chuyển môn (như tòa án). Tính tự lập được đánh giá rất cao trong những xã hội này.

Hệ thống văn hóa quyết định cấu trúc thể chế, tao ra tính phu thuộc vào quỹ đạo lịch sử của thể chế, cũng như tạo sự hiệu quả trong việc áp dụng những định chế mới. Nói cách khác, sự khác biệt hệ văn hóa trong tiến trình phát triển kinh 
tế - xã hội có tầm quan trọng trải suốt chiều dài lịch sử nhân loại. Lịch sử đã cho thấy mối quan hệ tương tác giữa các yếu tố: văn hóa, phương thức tổ chức xã hội và tăng trưởng kinh tế. Mối quan hệ qua lại này được phản ánh qua quá trình phát triển thể chế trong xã hội hiện đại.

\section{MộT VÀI ĐẶC ĐIỂM}

Trong hệ thống văn hóa luôn tồn tại một cấu thành mang tính quan niệm. Cấu thành này kết nối với ý thức con người và việc diễn đạt khách quan ý thức ấy được thông qua những yếu tố vật chất. Giới nghiên cứu nhân chủng không xa lạ với điều này khi tìm hiểu hệ văn hóa, sự tiến hóa cộng đồng người xa xưa và các đồ tạo tác văn hóa.

Tuy nhiên, ngay cả khi văn hóa phản ánh tổng thể cuộc sống xã hội - qua hệ giá trị, sự thực hành, các biểu trưng, thể chế và tập hợp các mối quan hệ giữa con người - thì tính hữu dụng của văn hóa trong việc giải thích thực tiễn xã hội và quá trình tiến hóa xã hội lại không mặc nhiên tồn tại và được công nhận. Vấn đề nằm ở chỗ mà Bornschier gọi là "độ tự do được biểu đat trong văn hóa". Sự biến thiên của nhân tố này bắt đầu với cách thức tư duy và tưởng tượng của cá nhân về những thế giới khác, cũng như sự điều chỉnh giữa những bộ óc có khả năng nhận thức được những gì đang diễn ra (Bornschier, 2005). Tầm ảnh hưởng của văn hóa cũng thể hiện ở chỗ, bất kể nhận thức hay tưởng tượng về một thế giới khác biệt, thì văn hóa áp đặt việc hình thành phương thức ứng xử với thế giới này như thể đó là cách duy nhất đúng, hợp lý và đáng trân trọng. Đây cũng là nguyên lý tạo ra các hành vi đặc trưng tương ứng với các nhóm văn hóa nhất định.

Xã hội bị chi phối đồng thời bởi hai hệ tư tưởng quyết định sự hình thành và bảo tồn giá trị: chuẩn tắc và thực chứng. Trong một hệ văn hóa luôn tồn tại sự khác biệt (có khi còn xung đột) giữa kiến thức thực chứng thu nhận từ đời sống thường nhật - những thứ làm nên tính đồng nhất và ý nghĩa đúc rút từ thực tiễn - và khả năng tưởng tượng những lựa chọn thay thế. Do sự xung khắc này, văn hóa không hoàn toàn cố định, mà chî̉ có mức độ ổn định cao. Đây là cơ sở cho tính tương đồng giữa văn hóa và quyền lực: sự dung hòa thông qua các mối quan hệ xã hội (Woolcock, 1998).

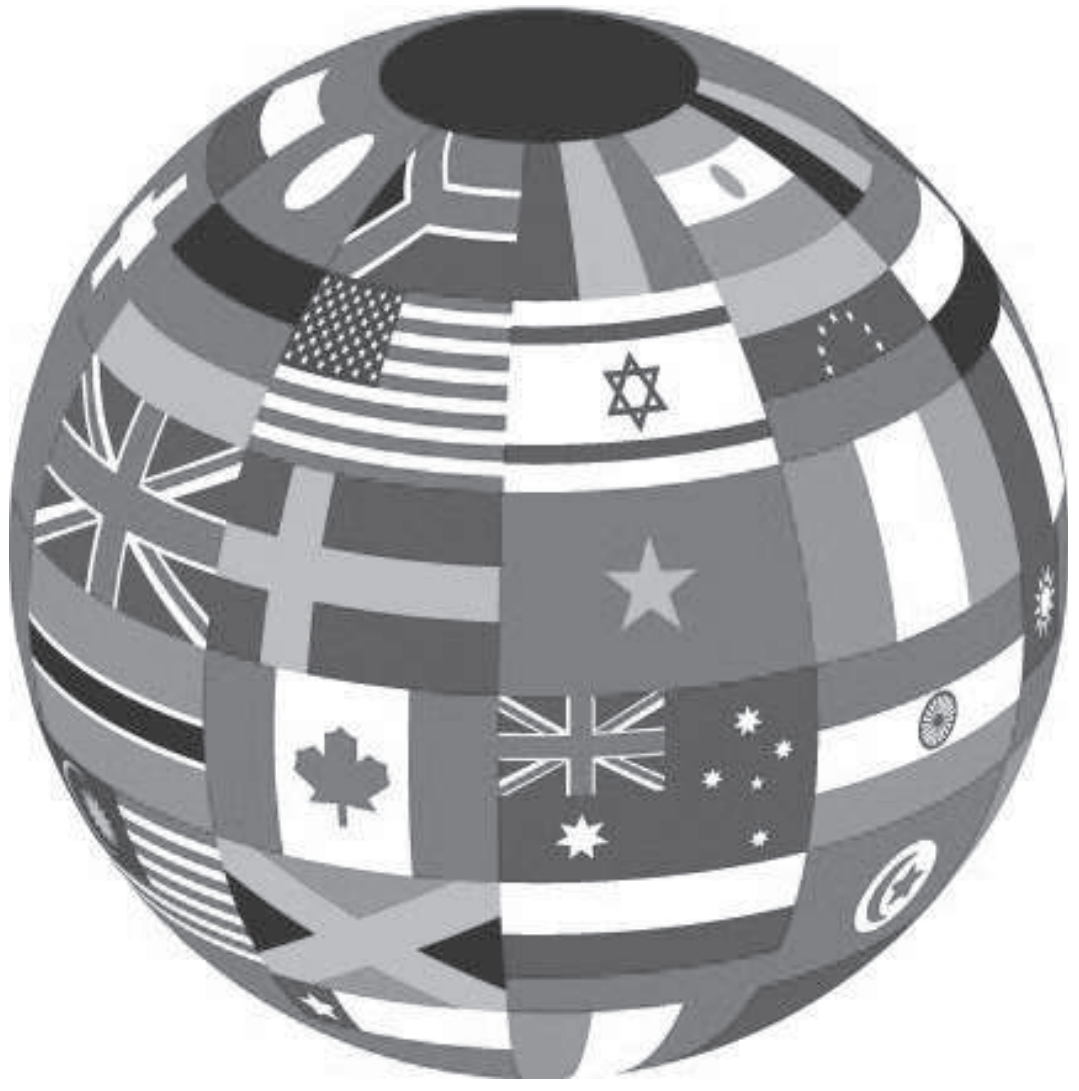

Hệ văn hóa hấp dẫn và cuốn hút một phần vì hầu như không thể dự báo các thành phần nếu chỉ dựa trên các điều kiện vật chất thuần túy. Có bằng chứng chỉ ra rằng, độ tin cậy tổng quát trong xã hội có quan hệ rất yếu với mức độ thịnh vượng của xã hội đó. Đồng thời, qua vị thế xã hội của một cá nhân cũng hầu như không thể dự báo về lòng tin của người khác về cá nhân đó. Các hệ văn hóa về nhận thức có thể tồn tại trong xã hội không có thang bậc chính trị, song, ở thế giới hiện đại, trật tự xã hội được bảo vệ bởi hệ thống nhà nước, trật tự đó là hiện thân của văn hóa đã được thể chế hóa ở cấp độ tập thể.

Dưới góc độ của nhà nước - đại diện cho ý chí xã hội - và phần lớn người dân, sự phát triển chính là kết quả từ việc văn hóa hỗ trợ kết cấu xã hội vận hành suôn sẻ. Điều này phù hợp với cách hiểu về sự tiến hóa trong hệ thống tri thức con người, được phản ánh qua kiến tạo luận do Jean Piaget (1896-1980) đề xướng. Về bản chất, kiến tạo luận dựa trên cơ sở con người tạo ra tri thức và sự tác động qua lại của kinh nghiệm và ý tưởng (Phillips, 1995).

Thông qua quá trình học tập, hệ thống văn hóa duy trì sự tồn tại, phân công chức năng và định hướng phát triển của hệ thống xã hội. Văn hóa có ảnh hưởng sâu rộng như vậy, trước hết là vì các quốc gia không thể hình thành nếu không tồn tại nền tảng văn hóa (Smith, 2008). Thứ nữa, xét trên quy mô toàn cầu, văn hóa là một trong những tác nhân hàng đầu quyết định quỹ đạo phát triển của hệ thống kinh tế trong một xã hội, cũng như vị thế tương đối trong một khu vực, hay giữa các khu vực. Điều này rất có ý nghĩa về nhận thức và chính sách (Hiwaki, 2014). 


\section{SƯ TIẾP BIẾN VĂN HÓA VÀ PHÁT TRIỂN KINH TẾ Ở VIỆT NAM}

Trong tiến trình Đổi mới, quá trình phát triển kinh tế - xã hội đã đẩy nhanh công cuộc chuyển đổi toàn diện xã hội Việt Nam. Tuy văn bản ghi nhận mốc khởi đầu Đổi mới là sau Đại hội Đảng VI vào cuối năm 1986, nhưng thực tế công cuộc cải cách xuất hiện sớm hơn nhiều nhờ công lao của "Bí thư khoán hộ" Kim Ngọc, các cố Tổng Bí thư: Trường Chinh, Nguyễn Văn Linh, cố Thủ tướng Võ Văn Kiệt...

Đặc biệt, phải kể đến nỗ lực không ngừng của khu vực tư nhân suốt một thời gian vật lộn, chống đỡ với khó khăn kinh tế để vươn lên, phát triển (Hoang \& associates, 2011). Nhìn sâu vào bản chất, quá trình này đặc trưng cho sự tiếp biến văn hóa rất mạnh mẽ, tởi mức tư tưởng cải cách đã được khơi thông. Đây là một quá trình học tập xã hội xảy ra trong các bộ phận: dân cư, người khởi nghiệp và doanh nghiệp nhỏ, lãnh đạo địa phương và lãnh đạo chính trị quốc gia, cũng như giữa các bộ phận này với nhau. Quá trình tiếp biến văn hóa thông qua học tập xã hội có thể được xem như dấu hiệu báo trước của Đổi mới và có thể gọi đây là sự hình thành và tái củng cố của một hệ thống văn hóa định hướng phục hồi phát triển, thông qua tư duy, hệ giá trị, các phương tiện và quy luật/quy tắc có tính thị trường trên quy mô cả nước.

Hệ thống văn hóa canh tân ấy lớn mạnh nhanh chóng, đưa xã hội và nền kinh tế Việt Nam ra khỏi tình trạng trì trệ và khủng hoảng cuối những năm 1980, tạo ra những thành tựu giúp củng cố nền tảng dân sinh và tiềm lực nhà nước, tái ổn định hệ thống xã hội. Quá trình cải cách thể chế - mà nhiều lãnh đạo và chuyên gia kỳ vọng sẽ đóng vai trò quan trọng trong Đổi mới II
- thực chất cũng chứa đựng nội dung tiếp tục củng cố hệ giá trị văn hóa quốc gia, trong bối cảnh mức tích lũy cao hơn và quá trình tiếp biến văn hóa đã tiếp cận, sàng lọc và quy nạp giá trị thị trường ở trình độ tổ chức tinh tế hơn sau 30 năm đổi mới. Quá trình tiếp biến văn hóa cũng diễn ra trước áp lực môi trường thay đổi nhanh do toàn cầu hóa và những hiệp định quốc tế mà Việt Nam tham gia.

Như thế, hệ thống văn hóa có thể xem như ADN (gen di truyền) của cơ thể xã hội, quy định hình dáng, kết cấu, tập tính, sự tác động qua lại của các thành phần và cơ hội thích nghi, phát triển lâu dài. $\mathrm{ADN}$ xã hội có độ ổn định tương đối cao, nhưng cũng hoàn toàn có khả năng thay đổi khi gặp stress từ môi trường bên ngoài hoặc từ bên trong; thậm chí, có những đột biến theo hướng tiến hóa, khiến hệ thống tự tách ra khỏi tiến trình bình thường. Ví dụ điển hình là hệ thống văn hóa Sillicon Valley. Mặc dù kế thừa rất nhiều giá tri tinh hoa của các nước phát triển châu Âu, nhưng thung lũng công nghệ này lại chửa đựng hệ văn hóa mà không một nước châu Ầu nào - kể cả Anh, Đức và Pháp - có được: đó là "văn hóa không sợ hãi" theo cách gọi của James B. Stewart. Sillicon Valley không hạ nhục người khởi nghiệp bất thành; và $\mathrm{ADN}$ của nó truyền tải qua khẩu quyết đơn giản nhưng khó thực hiện: Thất bại nhanh, thất bại thường xuyên - Fail fast, fail often (James B. Stewart, 2015).

\section{TÀI LIỆU THAM KHẢO}

1. Panagiotis E. Petrakis (2014). Culture, growth, and economic policy, Springer, Berlin, Germany

2. Lawrence E. Harrison and Samuel P. Huntington (2010). Culture matters: how values shape human progress, Basic Books, New York

3. Volker Bornschier (2005). Culture and politics in economic development, Routledge, New York

4. Avner Greif (1994). Cultural beliefs and the organization of society: a historical and theoretical reflection on collectivist and individualist societies, Journal of Political Economy, 102(5): 912-950

5. Michael Woolcock (1998). Social capital and economic development: toward a theoretical synthesis and policy framework, Theory and Society, 27(2): 151-208

6. Denis Charles Phillips (1995). The good, the bad, and the ugly: the many faces of constructivism, Educational Researcher, 24(7): 5-12

7. Anthony D. Smith (2008). The cultural foundations of nations: hierarchy, covenant, and republic, Blackwell, Malden

8. Kensei Hiwaki (2014). Culture and economics in the global community: a framework for socioeconomic development, Gower, Burlington

9. Quan Hoang Vuong, Van Nhue Dam, Daniel van Houtte, and Tri Dung Tran (2011). The entrepreneurial facets as precursor to Vietnam's economic renovation in 1986, The IUP Journal of Entrepreneurship Development, VIII(4): 6-47

10. James B. Stewart (2015). A Fearless Culture Fuels U.S. Tech Giants, access to http://www. nytimes.com/2015/06/19/business/the-american-way-of-tech-and-europes.html?_r=0 